\title{
Extraordinária concentração de andorinhas grandes (Progne modesta) em Iquitos, Peru
}

\author{
David C. Oren \\ Instituto Nacional de Pesquisas do Amazónio, \\ Manaus, e Harvard University, Cambridge
}

O gênero Progne (Aves: família Hirundinidae) é famoso por ter espécies que fazem grandes concentrações nos lugares de descanso. Este comportamento é bastante acentuado nas espécies migratórias, como P. subis da A.mérica do Norte, que regularmente descansa em grupos de até 100.000 indivíduos, durante o fim do verão norte-americano, antes de sair do lugar de reprodução (Allen e Nice, 1952). O uiriri (P. tapera) da América tropical (Panamá até Argentina) freqüentemente descansa em grupos de milhares de indivíduos "nos edifícios industriais, onde suas fezes criam dispendiosos problemas de limpeza e de segurança" (de Schauensee e Phelps, 1978). Uma das maiores concentrações de aves terrestres já notada foi feita por 1.000 .000 de indivíduos da espécie Hirundo rustica, na África do Sul (Rudebeck, 1955).

Embora estas grandes congregações sejam bem documentadas em outras espécies, não existe relatório sobre tal comportamento na espécie sul-americana Progne modesta ("andorinha grande") que no momento desta observação se encontrava um grupo imenso na cidade amazônica peruana de Iquitos. Durante uma visita nesta cidade, de 13-16 de setem- bro de 1978 , notei uma concentração de aproximadamente 100.000 indivíduos desta espécie e cerca de 5.000 P. subis.

Os pássaros descansavam na Plaza de Armas, que fica ao lado do centro comercial da cidade, distante uma quadra do Rio Amazonas (figura 1). Normalmente, a praça é um oásis cle verde, no meio de uma área grande de concreto e edifícios, com grama e grandes jambeiros (Eugenia malaccensis, Mystaceae) (figura 2). Numa quadra ao sudoeste da praça há mais jambeiros à beira da estrada; um menor número de andorinhas repousava lá durante a noite. Outras espécies de andorinhas escolhem bosques pequenos, freqüentemente perto da água, para seus lugares de descanso (Skutch, 1960). Embora a praça de lquitos fique no meio de uma povoação, é bem parecida com os lugares clássicos preferidos por essas espécies.

A chegada diária dos pássaros era impressionante. Os seguintes dados foram tirado do ineu caderno de campo.

14. 09.78

17:00 Observo cerca de 200 andorinhas caçando insetos no ar, entre a praça e o meio 


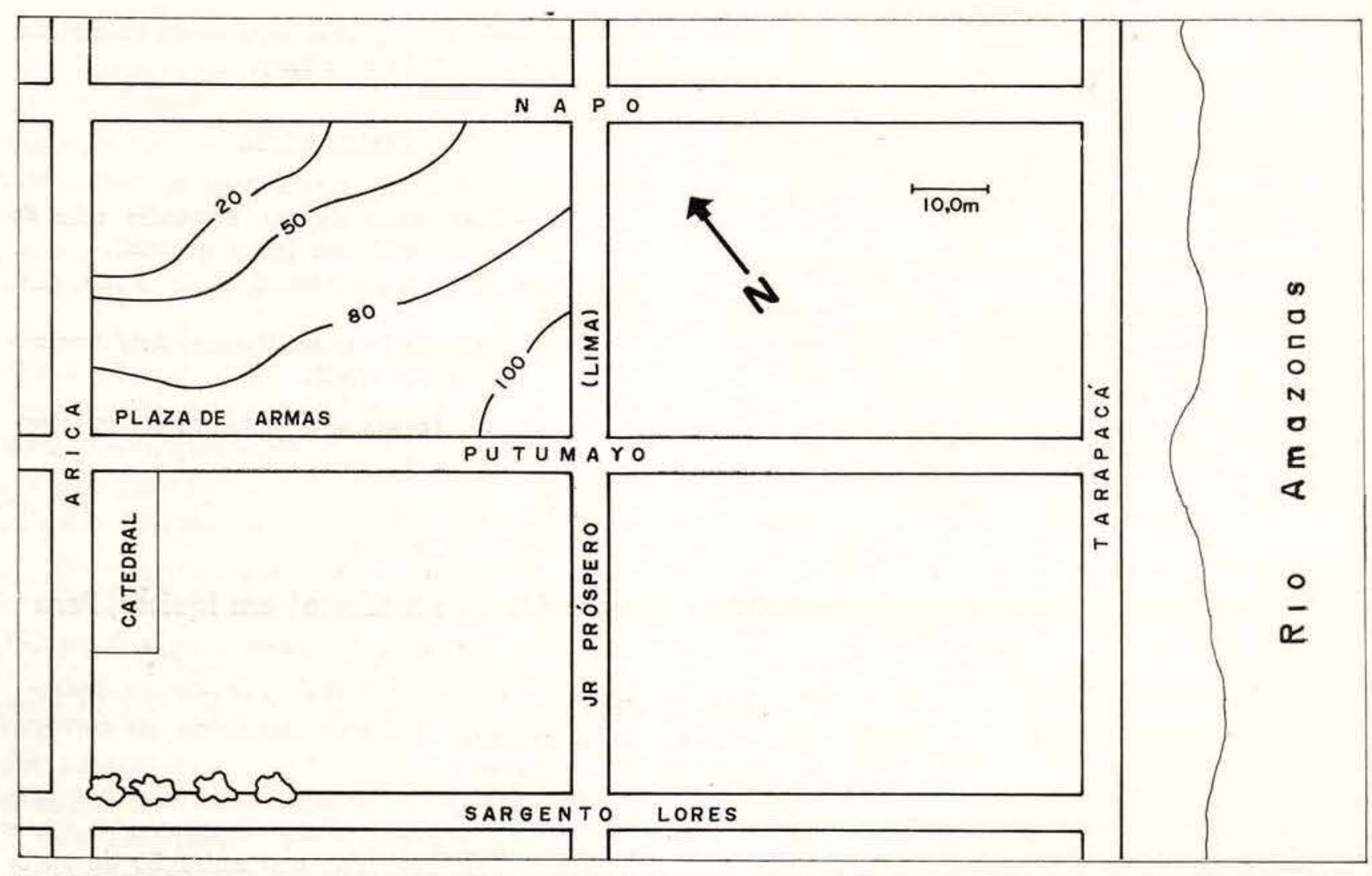

Fig. 1 - Mapa de lquitos, Peru, com a densidada de andorinhas grandes na Plaza de Armas.

do rio e outras cem descansando na fachada sıl de um edifício em construção, no lado nordeste da praça.

17:35 O número ainda não aumentou muito, com apenas 500 indivíduos na fachada do edifício ou caçando.

17:00 Ouço um barulho fraco de milhares de vozes se aproximando. Manchas pretas aparecem de todos os cantos do céu numa altitude de \pm 100 metros. O número aumenta até que os pássaros escurecem o céu, formando um enorme círculo girando em sentido contrário aos ponteiros do relógio. Cada vez, mais aves entram no círculo, que de repente, quando o sino da catedral dobra 18 horas, o círculo se parte lançando uma coluna de pássaros, como um sacarolha, para a terra. A cada volta da coluna, os pássaros voam mais rapidamente $\theta$ c espetáculo parece um verdadeiro furacão de aves. $O$ barulho é cada vez maior. Atingem a praça, brecam rapidamente e pousam nas árvores. As restantes descem e a praça fica cheia de andorinhas em apenas cinco minutos.
18:00 Fim da chegada dos pássaros: Por do sol.

As andorinhas ficaram a noite inteira na praça, partindo com as primeiras luzes do dia. Quando algumas pessoas perturbam as aves durante a noite, pequenos bandos deixam os ramos, voam em redor da praça, e voltam ao mesmo lugar ou a um outro próximo. Há sem-

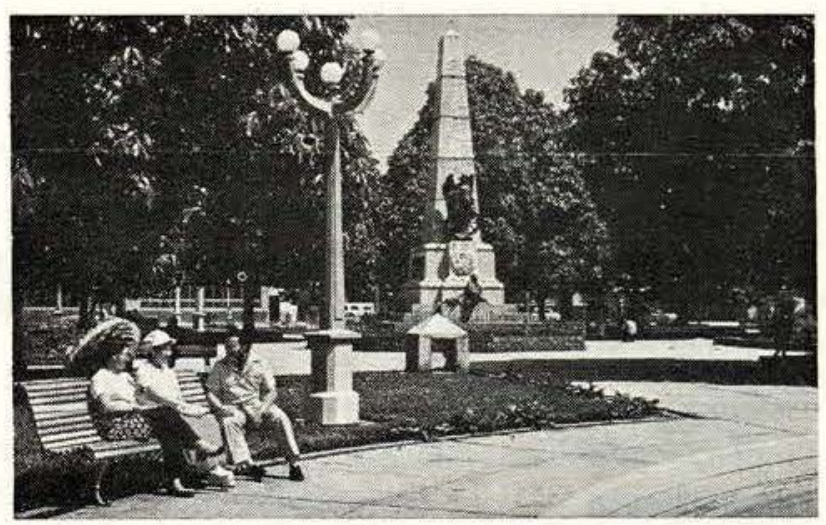

Fig. 2 - A Plaza de Armas em lquitos, um oásis de jambeiros e grama. 
pre o chilrear de milhares de pássaros na pra. ça, mas em menor intensidade, se não são mo lestados.

As andorinhas eram desconhecidas em Iquitos antes de 1976; nesse ano 300-600 delas ficaram três meses na praça, chegando em abril e partindo em julho. Em 1977 chegaram aproximadamente $25.000 \mathrm{em}$ abril permanecendo até a primeira semana de outubro ou a última semana de setembro (Rogério Castro, comm. pess.). Em 1978, chegou durante abril um bando de cerca de 250.000 andorinhas em poucos dias. Todas permaneceram até a terceira semana de agosto, quando aconteceu uma grande perturbação à população e o seu número diminuiu para menos da metade. É que, nessa semana o prefeito mandou cortar tudas as árvores da praça, para tentar expulsar as aves. Progne modesta tem machos uniformemente preto-azulados, enquanto as fêmeas e os jovens são pardos escuros. Embora muitas pessoas na cidade gostem dos pássaros e venham todos os dias observar sua chegada, outras acham, esses pássaros de plumagem escuras, um mau agouro para o futuro da cidade. Há também o problema das fezes na praça, que requer uma limpeza diária, e que, parcialmente, desfolharam a parte superior dos jambeiros. As árvores foram cortadas mais ou menos a 15 de agosto. Quando os pássaros chegaram para pernoitar, não havia locais para descansar. A maioria continuou girando ao redor da praça até cair do céu completamente exaustos, batendo em carros, janelas, pessoas e edifícios. Parece que milhares morreram. O povo de lquitos comeu muitos pássaros, e a andorinha chegou a aparecer por certo tempo no cardápio do restaurante chinês da cidade. O pessoal do Projeto Primatas, com sede em Iquitos, agiu rapidamente em favor das andorinhas, construindo "árvores falsas" de varas e prendendo cordas com varas suspendidas entre as árvores, como uma grande série de trapézios. Os pássaros voltaram, mas em número muito menor do que antes. Com essa fisionomia, encontrei a praça quando cheguei. (figura 3 ).

Progne modesta, como a maioria das espécies do gênero, é migratória . A espécie se re- produz na Argentina, Bolivia e Paraguai, voando para o Peru e Colômbia durante o inverno do sul. Chegando no Peru em abril, as andorinhas regressam para o sul, antes da segunda semana de outubro. Em 1978, as andorinhas de Iquitos, sairam da praça durante a primeira semana de outubro.

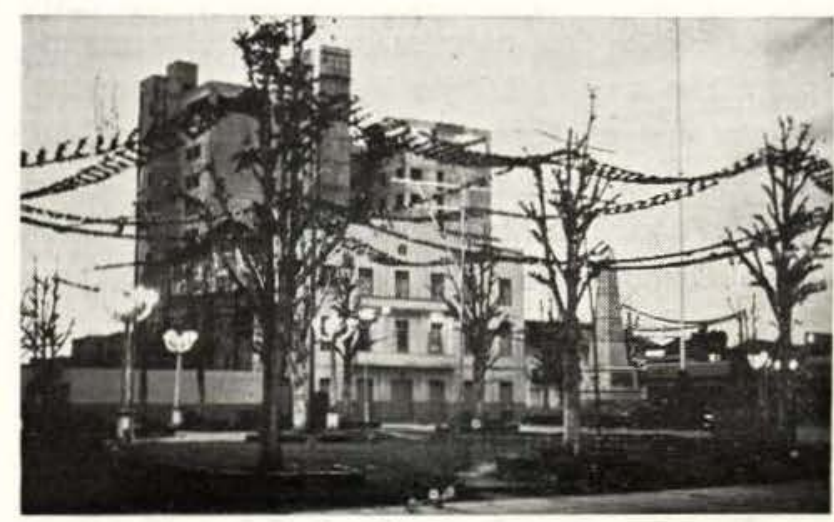

Fig. 3 - A Plaza de Armas em lquitos: Aspecto depois da corta das árvores. 05:50 horas, 15 de setembro de 1978. As manchas escuras săo andorinhas grandes (Progne modesta).

Durante esta pesquisa, sobre os pássaras, em Iquitos, os indivíduos năo se distribuiam por igual na praça (figura 1). Houve uma notável preferência pela parte sul da praça. Ao retirarem-se (da praça), pela manhã, os pássaros saíram por cima da Rua Jr. Próspero e depois para o rio mais ou menos em direção ao sul. É provável que este comportamento represente uma "inquietude migratória" da espécie (Emlen, 1969), e que sua preferência para o sul indique sua crescente prontidāo para partir para os lugares de reprodução no sul.

As andorinhas de lquitos constituem um espetáculo natural impressionante. Com proteção na cidade, elas poderiam voltar anualmente, tornando-se em grande atração turística. Elas comem milhōes de insetos diariamente, inclusive mosquitos e carapanãs. A presença delas requer limpeza da praça, mas também confere vantagens à cidade. As andorinhas são um recurso natural que a cidade pode utilizar ou expulsar. 


\section{AGRADECIMENTOS}

Agradeço ao Sr. Rogério Castro, do Projeto Primata, pelas informações sobre a história das andorinhas na cidade; ao Dr. Guilhermo Cetraro que ajudou na identificação das espécies; ao Dr. Peter Huijing que com generosidade, emprestou-me sua máquina fotográfica; ao Eng. Ramón Ruiz, do Ministério da Agricultura, que deu permissão de coletar exemplares; e ao Sr. Lórgio Verdi, que ajudou na coleta dos pássaros. Esta pesquisa recebeu auxílio financeiro de: The Charles A. Lindbergh Fund, The Museum of Comparative Zoology (Cambrindge, USA) e The National Geographic Society.

\section{SUMMARY}

The avian genus Progne (martins) is well known for its tendency to roost in aggregations of thousands of individuals. A concentration of approximately 100.000 Progne modesta (southern martins) with 5.000 P. subis (purple martins) in the Peruvian Amazon city of Iquitos in September 1978 is described, with a history of the species occurance in the area. Up to 250.000 individuals of the two species roosted in the Plaza de Armas of Iquitos from April to mid-August 1978, when trees used as roosting sites were cut in an attempt to drive the birds away. By virtue of a rescue effort to replace the lost perches, 100.000 birds were still found in the plaza in mid-September, the remainder having died or left.

In September the birds distinctly preferred the southern quadrate of the plaza, and the significance of this distribution in relation to migratory restlessness is discussed. All birds left the plaza by the first week in October, presumably to fly south to breeding grounds in Argentina, Bolivia and Paraguay.

\section{BIBLIOGRAFIA}

AILEN, R.W. \& NICE, M.M.

1952 - A study of the breeding biology of the purple martin (Progne subis). Amer. Midl Nat., 47: 606-665.

De Schauensee, R.M. \& Phelps, JR., W.H.

1978 - A guide to the birds of Venezuela. Princeton Univ. Press, Princeton, N.J., U.S.A. 424 pp.

ENilen, S.T.

1969 - Birds migration: influence of phisiological state upon celestial migration. Science, 165: $716-718$.

RUDEBECK, G.

1955 - Some observations at a roost of European swallows and other birds in the southeastern Transvaal. Ibis, 97: 572-580.

SKutch, A.F.

1960 - Life histories of Central American birds, II. Pacific Coast Avifauna, 34: 1-573.

(Aceito para publicação em 27/09/79) 